Article

\title{
Chitosan/Poly(2-ethyl-2-oxazoline) Films with Ciprofloxacin for Application in Vaginal Drug Delivery
}

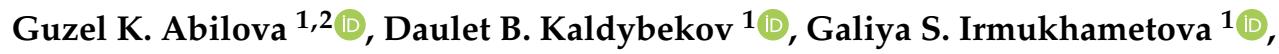 \\ Diara S. Kazybayeva ${ }^{1}\left(\mathbb{D}\right.$, Zhanar A. Iskakbayeva ${ }^{3}$ (D), Sarkyt E. Kudaibergenov ${ }^{4}$ and \\ Vitaliy V. Khutoryanskiy ${ }^{5, *(D)}$ \\ 1 Department of Chemistry and Chemical Technology, Al-Farabi Kazakh National University, Almaty 050040, \\ Kazakhstan; guzelab82@mail.ru (G.K.A.); dauletchem@gmail.com (D.B.K.); galiya.irm@gmail.com (G.S.I.); \\ diara_92@mail.ru (D.S.K.) \\ 2 Department of Natural Sciences, K. Zhubanov Aktobe Regional State University, Aktobe 030000, Kazakhstan \\ 3 Microbiology Laboratory of the Scientific Center for Anti-Infectious Drugs, Almaty 050060, Kazakhstan; \\ zhanara_07_74@mail.ru \\ 4 Institute of Polymer Materials and Technologies, Almaty 050019, Kazakhstan; skudai@mail.ru \\ 5 Reading School of Pharmacy, University of Reading, Whiteknights, Reading RG6 6AD, UK \\ * Correspondence: v.khutoryanskiy@reading.ac.uk
}

Received: 4 March 2020; Accepted: 31 March 2020; Published: 6 April 2020

\begin{abstract}
Chitosan (CHI) and chitosan/poly(2-ethyl-2-oxazoline) (CHI/POZ)-based films were prepared by casting from aqueous solutions of polymer blends with different compositions. Ciprofloxacin was used as a model drug in these formulations. The weight, thickness, folding endurance and transparency of blend films were measured and characterised. All films had a uniform thickness $(0.06 \pm 0.01 \mathrm{~mm})$ and exhibited sufficient flexibility. The surface $\mathrm{pHs}$ of films ranged from $3.76 \pm 0.49$ to $4.14 \pm 0.32$, which is within the $\mathrm{pH}$ range suitable for vaginal applications. The cumulative release of the drug from the films in experiments in vitro was found to be $42 \pm 2 \%$ and $56 \pm 1 \%$ for pure $\mathrm{CHI}$ and $\mathrm{CHI} / \mathrm{POZ}$ (40:60) films, respectively. Drug-free chitosan/poly(2-ethyl-2-oxazoline) films showed weak antimicrobial activity against Escherichia coli. Drug-loaded $\mathrm{CHI}$ and $\mathrm{CHI} / \mathrm{POZ}$ films showed good antimicrobial properties against both Gram-positive Staphylococcus aureus and Gram-negative bacteria Escherichia coli. Mucoadhesive properties of these films with respect to freshly excised sheep vaginal mucosa were evaluated using a tensile method. It was established that all films were mucoadhesive, but an increase in POZ content in the blend resulted in a gradual reduction of their ability to stick to vaginal mucosa. These films could potentially find applications in vaginal drug delivery.
\end{abstract}

Keywords: chitosan; poly(2-ethyl-2-oxazoline); films; antibacterial activity; mucoadhesion; drug release; vaginal drug delivery

\section{Introduction}

Vaginal drug administration has traditionally been used for the delivery of contraceptive agents and hormones as well as for local therapy of infections [1]. The vaginal route has several advantages, including the possibility to avoid first-pass metabolism, ease of administration and high permeability for small molecules.

The dosage forms traditionally used for vaginal drug delivery include creams, gels, pessaries, tablets, and elastomeric rings [2-5]. Mucoadhesive polymeric films have also received interest as a potential formulation strategy for vaginal delivery of contraceptives, microbicides and antimicrobial agents [6]. 
All water-soluble polymers have some ability to adhere to mucosal tissues, i.e., they exhibit mucoadhesive properties [7,8]. Typically, charged polymers of higher molecular weight show greater ability to adhere to mucosal membranes compared to non-ionic and smaller macromolecules. When weak anionic polyelectrolytes such as poly(carboxylic acids) are used, their mucoadhesive properties are related to hydrogen bonding with mucins [9]. Cationic polymers have excellent mucoadhesive properties due to electrostatic interactions with anionic mucin [10-12].

Chitosan is a cationic polysaccharide that exhibits excellent mucoadhesive properties [13] and antimicrobial activity [14]. It has been widely used in the design of various formulations for transmucosal drug delivery. Some attempts were also reported on the modulation of mucoadhesive and other physicochemical properties of chitosan through its chemical derivatisation [15].

Some modulation in the properties of chitosan could also be achieved through simple blending with other non-ionic water-soluble polymers. Previously, blending of chitosan with some cellulose ethers has been used to modify mechanical and mucoadhesive properties of polymeric films for buccal drug delivery [16]. Blends of chitosan with poly(N-vinyl pyrrolidone) [17-20], poly(ethylene oxide) $[17,19]$ and poly(vinyl alcohol) $[17,21,22]$ were also studied extensively.

Poly(2-oxazolines) is an emerging class of polymeric materials that have found numerous biomedical applications [23,24]. Poly(2-ethyl-2-oxazoline) is one of the representatives of poly(2-oxazolines) family that is a non-ionic water-soluble polymer available commercially. The application of this material in the design of dosage forms for drug delivery has received a substantial interest in the last few years and it is often viewed as a potential alternative pharmaceutical excipient to well-established water-soluble polymers [25-28].

Recently, we reported the preparation of chitosan/poly(2-ethyl-2-oxazoline) films for application in ocular drug delivery [29]. The structure and physicochemical properties of these films were evaluated using Fourier-transformed infrared spectroscopy, thermal gravimetric analysis, differential scanning calorimetry, wide-angle $\mathrm{X}$-ray diffraction, tensile testing and scanning electron microscopy. These studies indicated a complete miscibility between the polymers in the blends. The films were evaluated as potential dosage forms for ocular drug delivery both in vitro and in vivo.

In this study, we report the preparation of chitosan/poly(2-ethyl-2-oxazoline) films loaded with ciprofloxacin as a model drug. In vitro drug release studies using a Franz diffusion cell were conducted. Antibacterial activity of drug-free and drug-loaded films against both Escherichia coli and Staphylococcus aureus was evaluated. Adhesion of the films to freshly excised sheep vaginal mucosa was studied using a tensile test.

\section{Materials and Methods}

\subsection{Materials}

Chitosan (CHI, $\mathrm{M}_{\mathrm{W}} \sim 310-375 \mathrm{kDa}$ with a degree of deacetylation of 75-85\%), poly(2-ethyl-2-oxazoline) (POZ, $\mathrm{M}_{\mathrm{W}} \sim 50 \mathrm{kDa}$ and PDI 3-4), hydrochloric acid solution ( $\mathrm{HCl}, 1 \mathrm{M}$ ), phosphate-buffered saline (PBS) tablets $\mathrm{pH}$ 7.4, ciprofloxacin (CF), bovine serum albumin, acetic acid, lactic acid, glucose and urea were purchased from Sigma-Aldrich (Gillingham, UK). A dialysis cellulose membrane tube (molecular weight cut-off $14 \mathrm{kDa}$ ) was purchased from Sigma-Aldrich (Gillingham, UK). All other chemicals were of analytical grade and used without further purification.

\subsection{Preparation of Films}

Polymeric films based on chitosan (CHI) and its blends with poly(2-ethyl-2-oxazoline) (POZ) were cast by the solvent evaporation method according to a protocol previously reported by our group with minor modifications [29]. 1\% w/v aqueous solutions of $\mathrm{CHI}$ and $\mathrm{POZ}$ were prepared by dissolving pre-weighed amount of dry polymers at room temperature. $\mathrm{CHI}$ solution $(\mathrm{pH} \sim 3.8)$ was prepared in $0.1 \mathrm{M} \mathrm{HCl}$ by stirring magnetically for $12 \mathrm{~h}$ prior to casting. POZ solutions ( $\mathrm{pH} \sim 6.8$ ) were prepared in deionised water and allowed to stir continuously for $1 \mathrm{~h}$. The prepared polymer solutions were mixed 
at different volume ratios and named as CHI (100), CHI/POZ: (80:20), (60:40) and (40:60). The $\mathrm{pH}$ of the combined solutions was in the range of 3.9-4.0. CHI/POZ solutions were magnetically agitated for $3 \mathrm{~h}$ until total homogeneous mixture was formed. Subsequently, each polymer blend $(5 \mathrm{~mL})$ was poured into $35 \mathrm{~mm}$ plastic Petri dishes and dried at room temperature for several days.

\subsection{Preparation of Ciprofloxacin-Loaded Films}

A stock solution of ciprofloxacin hydrochloride $(10 \mathrm{mg} / \mathrm{mL})$ was prepared by first dissolving $0.1 \mathrm{~g}$ of ciprofloxacin in $0.4 \mathrm{~mL}$ of $1 \mathrm{M} \mathrm{HCl}$, before making the total volume to $10 \mathrm{~mL}$. Then, $0.5 \mathrm{~mL}$ of ciprofloxacin hydrochloride solution was aspirated and added to $4.5 \mathrm{~mL}$ of each $\mathrm{CHI}$ and $\mathrm{CHI} / \mathrm{POZ}$ solutions followed by stirring for $2 \mathrm{~h}$, to make the final $0.1 \% w / v \mathrm{CF}$ in polymer blends. Afterwards, prepared solutions were cast and dried as mentioned above. The content of ciprofloxacin in each film of $35 \mathrm{~mm}$ in diameter was $5 \mathrm{mg}$.

\subsection{Characterisation of Films}

\subsubsection{Film Thickness and Weight}

Physical measurements such as film thickness and weight were determined according to a previously described protocol [30]. Three film samples with a diameter of $35 \mathrm{~mm}$ from each formulation were individually weighed using an analytical balance. The thickness of the films was measured at five randomly selected positions including the middle part using a digital calliper. The mean \pm standard deviation values were calculated and are shown in Table 1.

\subsubsection{Folding Endurance}

Three samples from each film formulation were cut into $2 \times 2 \mathrm{~cm}$ squares. The folding endurance was determined according to the methodology reported in [31] by repeatedly folding the film at $180^{\circ}$ longitudinally at the same place until breakage. The film exhibiting folding endurance value $\geq 300$ without breaking is considered to have excellent flexibility.

\subsubsection{Surface $\mathrm{pH}$ Measurements}

Each film formulation was cut into discs with the diameter of $10 \mathrm{~mm}$, then placed in plastic Petri dishes (40 mm in diameter) and allowed to swell in contact with $1.5 \mathrm{~mL}$ of distilled water at room temperature for $30 \mathrm{~min}$. Surface $\mathrm{pH}$ was measured using a glass electrode $781 \mathrm{pH} / \mathrm{Ion}$ Meter placed on the surface of the swollen films. Each sample was analysed three times and the mean values \pm standard deviations were calculated.

\subsubsection{Transparency}

The transparency of the films was measured using an Analytik Jena Specord ${ }^{\circledR} 200$ Plus UV/Vis spectrophotometer (Jena, Germany) to determine the percentage of light transmittance for each sample $(1 \times 4 \mathrm{~cm}$ strips) at two different wavelengths $(400$ and $600 \mathrm{~nm})$ of visible light.

\subsection{Antimicrobial Studies}

Antibacterial activity of $\mathrm{CHI}$ and $\mathrm{CHI} / \mathrm{POZ}$ films with and without ciprofloxacin (CF) was examined against two model microorganisms such as Escherichia coli ATCC 8739 (Gram-negative bacteria) and Staphylococcus aureus ATCC 6538-p (Gram-positive bacteria) using disc diffusion method [32]. Briefly, samples were exposed to bacteria on solid media (nutrient agar) and inhibition zone around each sample was measured and recorded. First, active colonies of a number of microorganisms were cultured. These microorganisms were then diluted using $5 \mathrm{~mL}$ saline solution $(0.9 \% \mathrm{NaCl})$ until a colony count can be achieved which has the turbidity values of 0.5 a.u. equivalent to that of a McFarland standard solution $\left(1.5 \cdot 10^{8} \mathrm{CFU} / \mathrm{mL}\right)$. Then, bacterial inoculum $(1.5-2.0 \mathrm{~mL})$ was laid over the nutrient agar plate using a sterile cotton swab. Film samples ( $6 \mathrm{~mm}$ diameter discs) were placed on 
the agar plate using sterile forceps and incubated for $24 \mathrm{~h}$ at $37^{\circ} \mathrm{C}$. Inhibition zone for bacterial growth was measured to estimate its inhibitory effects (Table 2). A disc with pure antibiotic (CF) was used as a control sample.

\subsection{In Vitro Drug Release Experiments}

Release of CF from films was carried out using a dialysis method with Franz diffusion cell (FDC) under "sink conditions". The cellulose membrane was used as a barrier and placed between the donor and receptor compartments of FDC. The experiment was conducted using phosphate-buffered saline (PBS, $\mathrm{pH}=7.4$ ) as a medium solution. The volume of PBS in the receiving chamber of the cell was $30 \mathrm{~mL}$, which was stirred at $80 \mathrm{rpm}$ and maintained at $37^{\circ} \mathrm{C}$ throughout the experiment. Dry films with CF were placed directly on dialysis membrane in the donor compartment of FDC without any previous wetting and $1 \mathrm{~mL}$ of aliquots were taken from the receptor compartment at predetermined time intervals and replaced each time with $1 \mathrm{~mL}$ fresh medium (PBS) to maintain a constant volume. All release experiments were carried out during $8 \mathrm{~h}$. Three replicates were performed for each type of films.

The amount of released CF was determined using spectrophotometric technique at $272 \mathrm{~nm}$ with the help of an Analytik Jena Specord ${ }^{\circledR} 200$ Plus UV/Vis spectrophotometer (Jena, Germany). The percentage of drug released at each time point was calculated using a calibration curve (Figure S1 in Supplementary Information, $R^{2}=0.9999$ ).

\subsection{Ex vivo Mucoadhesion Studies on Sheep Vaginal Tissue}

The adhesiveness of the films to vaginal mucosa was studied using a tensile method with Texture Analyser XT Plus (Stable Micro Systems Ltd., UK) equipped with a cylindrical aluminium probe $\mathrm{P} / 25$ (25 $\mathrm{mm}$ in diameter). During testing, each film was cut into spherically shaped discs (10 $\mathrm{mm}$ in diameter), and then were attached to the probe with the help of double-sided adhesive tape, which was secured to the mobile arm of the texture analyser. Isolated sheep vaginal tissues were obtained from Altyn-Orda Abattoirs (Almaty, Kazakhstan) immediately after animal slaughter, frozen and were transported to the laboratory in a polystyrene container. The mucosal membranes were subsequently defrosted upon arrival and carefully dissected using a sharp blade, avoiding contact with the internal mucosa. Each mucosal tissue was affixed securely on the mucoadhesion rig and was moisturised with simulated vaginal fluid (SVF) prior to each testing. SVF was prepared according to the previous literature report [33] with the following composition: $\mathrm{NaCl} 3.51 \mathrm{~g} / \mathrm{L} ; \mathrm{KOH} 1.40 \mathrm{~g} / \mathrm{L} ; \mathrm{Ca}(\mathrm{OH})_{2} 0.222 \mathrm{~g} / \mathrm{L}$; bovine serum albumin $0.018 \mathrm{~g} / \mathrm{L}$; lactic acid $2.00 \mathrm{~g} / \mathrm{L}$; acetic acid $1.00 \mathrm{~g} / \mathrm{L}$; glycerol $0.16 \mathrm{~g} / \mathrm{L}$; urea $0.40 \mathrm{~g} / \mathrm{L}$; glucose $5.0 \mathrm{~g} / \mathrm{L}$. The $\mathrm{pH}$ of SVF was adjusted to 4.2 using $1 \mathrm{M} \mathrm{HCl}$.

During the adhesion tests, each film sample attached to the cylindrical probe was pressed onto the moist vaginal surface at a speed rate of $0.05 \mathrm{~cm} / \mathrm{s}$ and $0.981 \mathrm{~N}$ and remained in contact for $30 \mathrm{~s}$ to ensure complete attachment. Then the probe was withdrawn at a speed rate of $0.05 \mathrm{~cm} / \mathrm{s}$ and $0.001 \mathrm{~N}$ trigger force until complete detachment from the biological substrate. Data acquired from the detachment experiments were then used to evaluate the mucoadhesion strength, i.e., the maximum force required for the detachment $\left(\mathrm{F}_{\mathrm{adh}}\right)$ and the total work of adhesion (the area under the force/distance curve, $\mathrm{W}_{\mathrm{adh}}$ ) values (Figures S2 and S3 in Supplementary Information). All measurements were conducted five times for each film sample.

\subsection{Statistical Analysis}

Data obtained during these experiments, i.e., the mean values and standard deviations were calculated and compared for differences using two-tailed Student's $t$-test with GraphPad Prism statistical analysis software (GraphPad Software Inc., version 7.0; San Diego, CA, USA), where $p<0.05$ was used as a statistically significant criterion. 


\section{Results and Discussion}

\subsection{Preparation and Characterisation of Films}

Ciprofloxacin (CF) was used in the present work as a model antibiotic. In some sources, it is recommended as a therapeutic agent for the treatment of some vaginal infections [34]. Two types of samples were prepared: drug-free and CF-loaded films. Initially, all these films were evaluated for their physicochemical characteristics and properties such as thickness and weight, folding endurance, optical transparency, and surface $\mathrm{pH}$ (Table 1). All films had thicknesses in the range of 0.05 to $0.08 \mathrm{~mm}$. Drug loading did not make any substantial effects on the sample thicknesses.

The flexibility of a polymeric material is important when considering that the films will be administered intravaginally and this should not result in a breakage. One of the methods to assess film flexibility is the evaluation of its folding endurance, i.e., the number of times the sample could be folded at the same place without breaking. According to the literature [35], the films exhibiting folding endurance value greater than 300 are considered to have excellent flexibility. Our results indicated excellent flexibility for CHI (100) and CHI/POZ (80:20) films (both drug-free and drug-loaded), with each formulation remaining intact after $>300$ repeating folds (Table 1 ). Folding endurance was found to be highest for CHI (100) (1300 \pm 8$)$ and lowest for CHI/POZ (40:60) (65 \pm 5$)$. Thus, an increase in the POZ content in the film resulted in a decrease in the folding endurance.

All drug-free films were homogeneous, transparent and smooth, which is in good agreement with our previous study demonstrating complete miscibility between these two polymers [29]. However, the films containing ciprofloxacin were slightly opaque.

Transparency of the films was evaluated by measuring the light transmittance using UV/Visspectrophotometry at two wavelengths of visible light (400 and $600 \mathrm{~nm}$ ). Almost all the drug-free films showed light transmission values above 85\%, confirming their good transparency. Drug-loaded films exhibited much lower transparency with the light transmission values at 35.9-45.4\% at $400 \mathrm{~nm}$ and $65.1-78.2 \%$ at $600 \mathrm{~nm}$. An insufficient transparency of drug-loaded films could be a serious limitation in certain therapeutic areas, for example, in ocular drug delivery where it could interfere with normal vision. However, vaginal administration does not have a requirement for a dosage form to have particular transparency. The reduced transparency of drug-loaded films indicates that $\mathrm{CF}$ content in the samples exceeds its intrinsic solubility in these polymers in the solid state, resulting in its partial crystallisation.

The measurements of the samples' surface $\mathrm{pH}$ established that these materials have an acidic nature, with drug-free films exhibiting $\mathrm{pH} \sim 4.02-4.14$ and drug-loaded films showing slightly lower values $(\mathrm{pH} \sim 3.76-3.86)$. This acidic nature of the films makes them suitable for vaginal administration as the $\mathrm{pH}$ in a healthy adult vagina is also weakly acidic [36]. It may be concluded that vaginal $\mathrm{pH}$ will remain unaffected after administration of these films. 
Table 1. Physicochemical parameters of chitosan (CHI) and chitosan/poly(2-ethyl-2-oxazoline) (CHI/POZ) blend films.

\begin{tabular}{|c|c|c|c|c|c|c|c|}
\hline \multirow{2}{*}{ Samples } & \multirow{2}{*}{$\begin{array}{c}\text { Chemical } \\
\text { Composition }(\% \mathrm{v} / \mathrm{v})\end{array}$} & \multirow{2}{*}{$\begin{array}{l}\text { Thickness } \\
\text { (mm) }\end{array}$} & \multirow{2}{*}{ Weight (mg) } & \multirow{2}{*}{$\begin{array}{l}\text { Folding } \\
\text { Endurance }\end{array}$} & \multicolumn{2}{|c|}{ Transparency (\%) } & \multirow{2}{*}{ Surface $\mathrm{pH}$} \\
\hline & & & & & $400 \mathrm{~nm}$ & $600 \mathrm{~nm}$ & \\
\hline \multicolumn{8}{|c|}{ Drug-Free Films } \\
\hline A & CHI 100 & $0.07 \pm 0.01$ & $33.41 \pm 1.52$ & $>300$ & 85.6 & 89.8 & $4.06 \pm 0.37$ \\
\hline B & CHI/POZ 80:20 & $0.08 \pm 0.02$ & $33.67 \pm 2.51$ & $>300$ & 87.5 & 89.4 & $4.02 \pm 0.30$ \\
\hline $\mathrm{C}$ & CHI/POZ 60:40 & $0.06 \pm 0.01$ & $35.00 \pm 4.36$ & $<300$ & 88.2 & 89.9 & $4.08 \pm 0.33$ \\
\hline D & CHI/POZ 40:60 & $0.05 \pm 0.01$ & $33.33 \pm 2.08$ & $<300$ & 88.5 & 89.7 & $4.14 \pm 0.32$ \\
\hline \multicolumn{8}{|c|}{ Drug-Loaded Films } \\
\hline A1 & CHI 100 & $0.06 \pm 0.01$ & $35.25 \pm 2.29$ & $>300$ & 36.6 & 65.1 & $3.76 \pm 0.49$ \\
\hline B1 & CHI/POZ 80:20 & $0.07 \pm 0.01$ & $32.70 \pm 1.51$ & $>300$ & 45.4 & 68.1 & $3.86 \pm 0.22$ \\
\hline $\mathrm{C} 1$ & $\mathrm{CHI} / \mathrm{POZ}$ 60:40 & $0.06 \pm 0.01$ & $36.45 \pm 5.31$ & $<300$ & 35.9 & 72.9 & $3.78 \pm 0.42$ \\
\hline D1 & CHI/POZ 40:60 & $0.05 \pm 0.01$ & $38.83 \pm 1.83$ & $<300$ & 40.5 & 78.2 & $3.86 \pm 0.22$ \\
\hline
\end{tabular}




\subsection{Antimicrobial Activity}

Due to its cationic nature, chitosan is known to exhibit good antimicrobial activity against a wide range of microorganisms, such as bacteria, fungi and yeast $[14,37,38]$. However, these properties of $\mathrm{CHI}$ are greatly dependent on its physicochemical characteristics such as molecular weight, degree of deacetylation as well as biopolymer concentration, and environmental $\mathrm{pH}$.

Antimicrobial activity of $\mathrm{CHI}$ and $\mathrm{CHI} / \mathrm{POZ}$ films was studied against Staphylococcus aureus and Escherichia coli using the disc diffusion method. Figure 1 shows exemplar images from disc diffusion experiments and Table 2 summarises the data on the diameters of inhibition zones. It can be seen from these data that there is no suppression of the growth of Staphylococcus aureus strain for the film samples based on chitosan and poly(2-ethyl-2-oxazoline) without ciprofloxacin. Drug-free films of pure $\mathrm{CHI}$ also did not show any antimicrobial effects on Escherichia coli; however, $\mathrm{CHI} / \mathrm{POZ}$ blends exhibited some inhibition in the growth of these bacteria. Several reasons could be responsible for lack of antimicrobial activity exhibited by the films of pure CHI to both Staphylococcus aureus and Escherichia coli, and also of the polymer blend films to Staphylococcus aureus. First, it could be related to the nature of the disc diffusion method and inability of high-molecular $\mathrm{CHI}\left(\mathrm{M}_{\mathrm{W}} \sim 310-375 \mathrm{kDa}\right)$ to diffuse through agar gel and inhibit the growth of bacteria. Semi-crystalline nature of $\mathrm{CHI}$ also makes it insoluble at higher $\mathrm{pHs}$ and less diffusive. However, in the blends chitosan may be less crystalline and could diffuse better. Second factor is the sensitivity of different bacteria to antimicrobials and also to $\mathrm{pH}$. Perhaps, Escherichia coli is more sensitive than Staphylococcus aureus either to chitosan or to lower $\mathrm{pHs}$, displayed by the films.

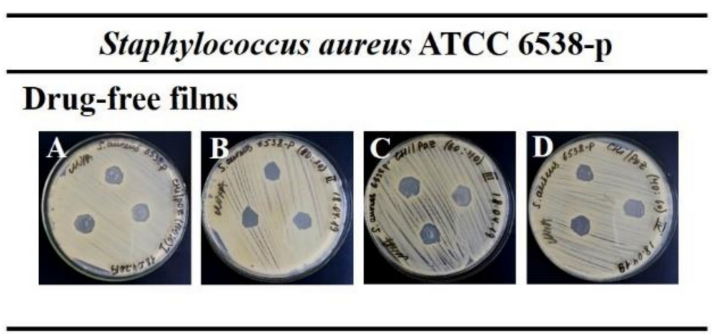

Drug-loaded films $(0.1 \%$ w/v CF $)$

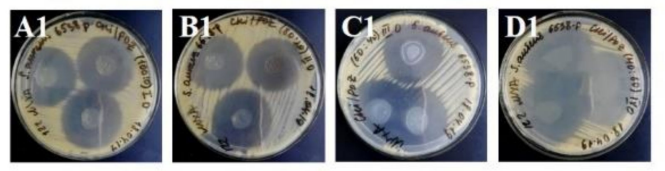

Control sample

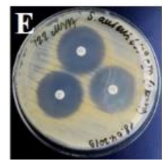

Escherichia coli ATCC 8739

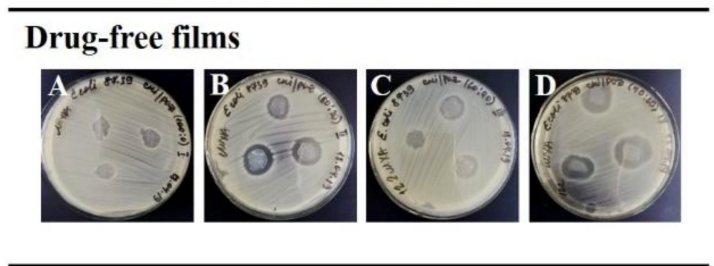

Drug-loaded films (0.1\% w/v CF)

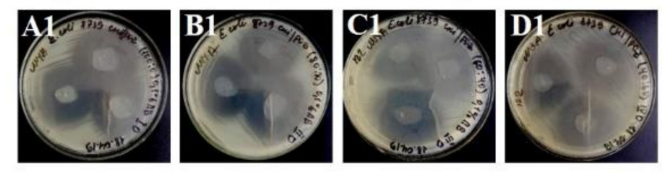

Control sample

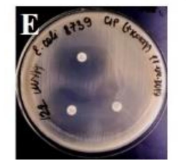

Figure 1. Inhibition zones of polymeric films against Gram-positive Staphylococcus aureus and Gram-negative Escherichia coli bacteria: A and A1-CHI (100); B and B1-CHI/POZ (80:20); C and C1—CHI/POZ (60:40); D and D1—CHI/POZ (40:60); and E-ciprofloxacin.

CF was used as a control sample in these microbiological experiments and demonstrated antimicrobial activity against both Staphylococcus aureus ATCC 6538-p (growth inhibition zone of $31.2 \pm 0.4 \mathrm{~mm}$ ) and Escherichia coli ATCC 8739 (growth inhibition zone of $35.1 \pm 1.2 \mathrm{~mm}$ ), which characterises these strains as sensitive to this antibiotic.

Ciprofloxacin-loaded (0.1\% w/v) polymeric films with CHI 100 (A1), CHI/POZ (80:20) (B1), $\mathrm{CHI} / \mathrm{POZ}$ (60:40) (C1) and CHI/POZ (40:60) (D1) were active against Staphylococcus aureus ATCC 6538-p and growth inhibition zones were in the range from $36.0 \pm 1.9 \mathrm{~mm}$ to $46.1 \pm 1.7 \mathrm{~mm}$. CHI/POZ films with ciprofloxacin also showed activity against Escherichia coli ATCC 8739 and displayed 
growth-inhibition zones in the range from $39.3 \pm 2.3 \mathrm{~mm}$ to $42.5 \pm 2.0 \mathrm{~mm}$, which indicates greater antimicrobial activity against this bacteria strain. Thus, using CHI/POZ films as excipients for formulating CF results in enhancement of their antimicrobial activity against Gram-negative strain Escherichia coli in comparison with pure CHI film and control sample of CF. Sensitivity to the Gram-positive strain, Staphylococcus aureus, was observed only for drug-loaded films.

Table 2. Antimicrobial activity of $\mathrm{CHI}$ and $\mathrm{CHI} / \mathrm{POZ}$ blend films.

\begin{tabular}{cccc}
\hline \multirow{2}{*}{ Samples } & Chemical Composition $(\% \mathbf{v} / \mathbf{v})$ & \multicolumn{2}{c}{ Diameter of Growth Inhibition Zone (mm) } \\
\cline { 3 - 4 } & \multicolumn{2}{c}{ Staphylococcus aureus } & Escherichia coli \\
\hline \multicolumn{5}{c}{ Drug-Free Films } \\
\hline A & CHI (100) & 0 & 0 \\
B & CHI/POZ (80:20) & 0 & $17.3 \pm 2.1^{* * *}$ \\
C & CHI/POZ (60:40) & 0 & $13.3 \pm 2.1^{* *}$ \\
D & CHI/POZ (40:60) & 0 & $21.0 \pm 2.0^{* * * *}$ \\
\hline \multicolumn{5}{c}{ Drug-Loaded Films (CF $\mathbf{0 . 1 \%}$ w/v) } \\
\hline B1 & CHI (100) & $38.6 \pm 1.3^{* * *}$ & $39.5 \pm 1.9^{*}$ \\
C1 & CHI/POZ (80:20) & $36.0 \pm 1.9^{* *}$ & $40.1 \pm 2.6^{* *}$ \\
D1 & CHI/POZ (60:40) & $38.6 \pm 1.6^{* * *}$ & $42.5 \pm 2.2^{* * *}$ \\
E & CHI/POZ (40:60) & $46.1 \pm 1.7^{* * *}$ & $39.3 \pm 2.3^{*}$ \\
\hline
\end{tabular}

$\overline{\mathrm{CHI}}$, chitosan; POZ, poly(2-ethyl-2-oxazoline); $\mathrm{CF}$, ciprofloxacin. Anti-microbial activity values of $\mathrm{CHI} / \mathrm{POZ}$ drug-free films and ciprofloxacin-loaded films were compared to pure $\mathrm{CHI}$ and discs with $\mathrm{CF}$, respectively. Statistically significant differences are given as: ${ }^{* * * *}-p<0.0001 ;{ }^{* * *}-p<0.001 ;{ }^{* *}-p<0.01 ;{ }^{*}-p<0.05$. Data are expressed as mean \pm standard deviation $(\mathrm{n}=3)$.

\subsection{In vitro Drug Release Studies}

The normal $\mathrm{pH}$ in the vagina of a healthy women of reproductive age is typically ranged within 3.8-4.2 [39]. This weakly acidic environment is due to lactic acid produced by the healthy vaginal microflora. However, in pathological vaginal conditions (e.g., bacterial vaginosis, trichomonas vaginalis, group B streptococcus or other pathogenic organisms), the $\mathrm{pH}$ may increase [40]. In order to model the vaginal environment with a pathological condition, the in vitro drug release studies from $\mathrm{CHI} / \mathrm{POZ}$ films were conducted in PBS solution at $\mathrm{pH}=7.4\left(37^{\circ} \mathrm{C}\right)$ using a dialysis membrane and the cumulative release profiles were calculated (Figure 2). CHI films showed the lowest drug release (no more than $45 \%$ ), which is possibly due to the electrostatic attraction between the amino-groups of $\mathrm{CHI}$ and carboxylic groups of ciprofloxacin hydrochloride. The presence of poly(2-ethyl-2-oxazoline) in $\mathrm{CHI} / \mathrm{POZ}$ films from $20 \%$ to $60 \% \mathrm{v} / \mathrm{v}$ resulted in an increase in drug released in the range of $51 \pm 3 \%$ to $56 \pm 2 \%$ during the $4 \mathrm{~h}$, respectively. In our previous study [29], we confirmed the formation of weak intermolecular hydrogen bonds between carbonyl groups of poly(2-ethyl-2-oxazoline) and both amine and hydroxyl groups of chitosan. Thus, the presence of poly(2-ethyl-2-oxazoline) in the blend films can reduce the concentration of chitosan, which eventually leads to less efficient binding of CF and as a result, the amount of released drug is higher for $\mathrm{CHI} / \mathrm{POZ}$ films in comparison with pure $\mathrm{CHI}$. This electrostatic binding between ciprofloxacin and chitosan could also be the reason for an incomplete drug release from the films (only 40-55\%). For all types of films, the drug release reaches the equilibrium value within approximately two hours. 


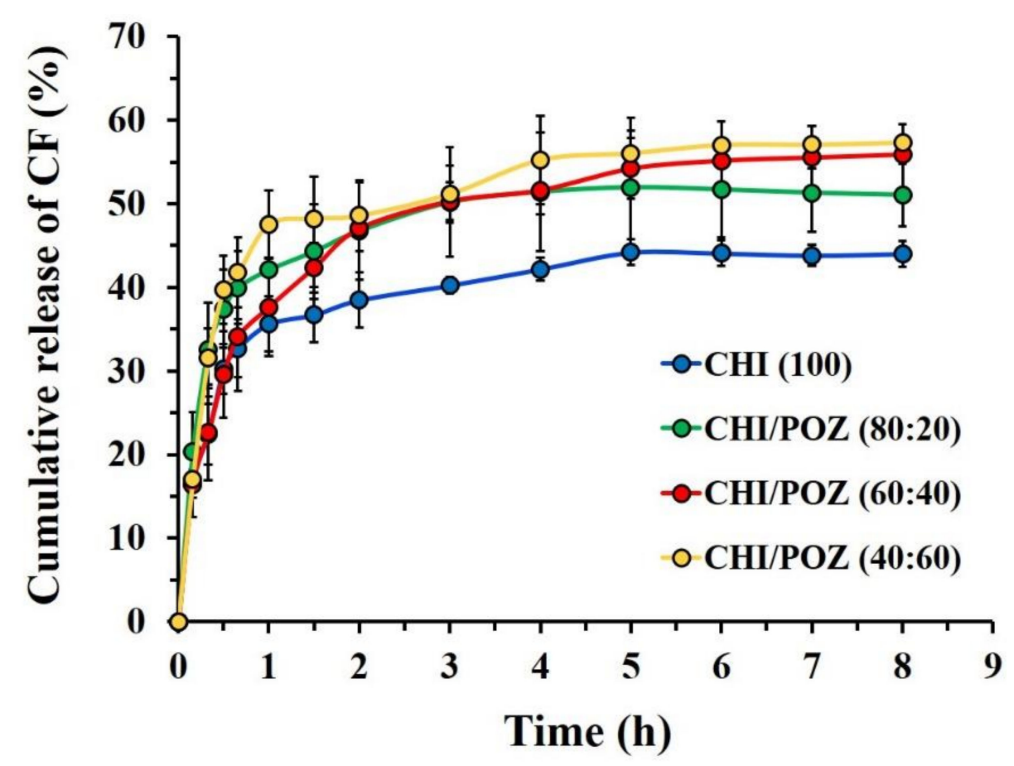

Figure 2. In vitro cumulative release of ciprofloxacin from chitosan ( $\mathrm{CHI}$ ) and chitosan/poly(2-ethyl-2-oxazoline) $(\mathrm{CHI} / \mathrm{POZ})$ films with different polymer ratios. Data are presented as mean \pm standard deviation $(\mathrm{n}=3)$.

\subsection{Ex Vivo Mucoadhesion Studies}

Mucoadhesive properties of films usually determine their residence on mucosal tissues. Films with good mucoadhesiveness are expected to retain on vaginal mucosa for a longer time and to maintain high drug levels at the site of administration [41]. The tensile method is one of the approaches widely used to evaluate mucoadhesive properties of various formulations, including films [42]. In this work, we have used freshly excised sheep vaginal tissues as a substrate for mucoadhesion studies. The values of maximum detachment force $\left(\mathrm{F}_{\mathrm{adh}}\right)$ and the total work of adhesion $\left(\mathrm{W}_{\mathrm{adh}}\right)$ for detachment of drug-free $\mathrm{CHI}$ and $\mathrm{CHI} / \mathrm{POZ}$ films from vaginal tissue were determined (Figure 3).
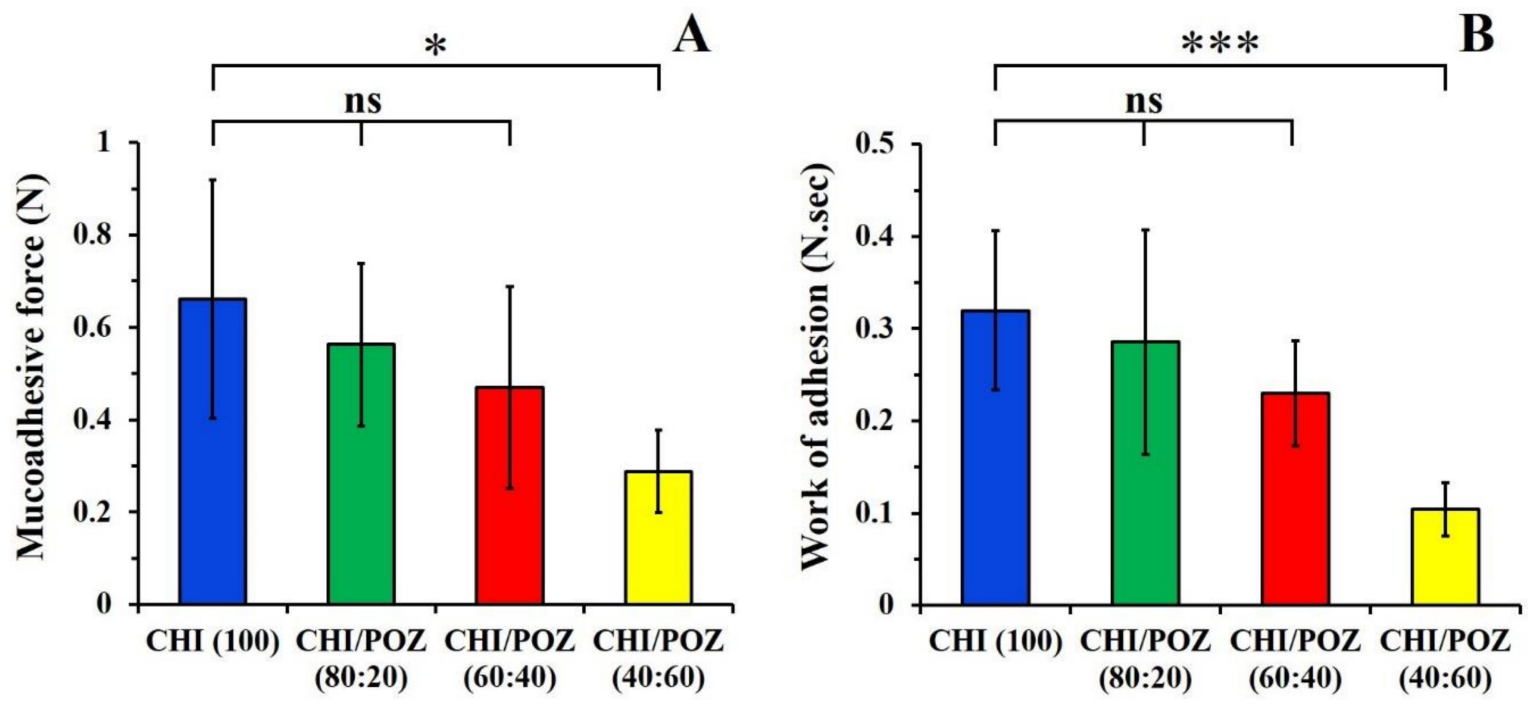

Figure 3. Detachment force $F_{\text {adh }}(\mathbf{A})$ and total work of adhesion $W_{\text {adh }}($ B) values for detachment of chitosan (CHI) and chitosan/poly(2-ethyl-2-oxazoline) (CHI/POZ) blend films from sheep vaginal mucosa. Data are expressed as mean \pm standard deviation $(n=5)$. Statistically significant differences are given as: ${ }^{*}-p<0.05 ;{ }^{* * *}-p<0.001 ; \mathrm{ns}-$ no significance.

Films based on pure chitosan exhibit strong mucoadhesive properties due to its cationic nature and electrostatic attraction to negatively charged mucosa. Additionally, its hydroxyl groups could also form hydrogen bonds with mucin [13]. On the contrary, poly(2-ethyl-2-oxazoline)s exhibit poor 
mucoadhesive properties $[15,43]$. The weak mucoadhesive nature of POZ can be explained by its non-ionic nature. An increase in $\mathrm{POZ}$ content in the films shows a gradual reduction in the detachment force and total work of adhesion values, which is consistent with the decrease in the concentration of more mucoadhesive component (chitosan). There is also a good correlation between $F_{a d h}$ and $W_{a d h}$ values. This trend is also in good agreement with our previous studies of mucoadhesive properties of chitosan blends with hydroxyethylcellulose (as a non-ionic component) with respect to porcine buccal mucosa [16].

Potentially, the films loaded with ciprofloxacin could also exhibit some reduction in their mucoadhesive properties compared to drug-free blends due to the inability of small drug molecules to contribute to adhesion. This trend was previously reported by us for chitosan tablets loaded with ibuprofen [44].

\section{Conclusions}

Polymer blends of chitosan and poly(2-ethyl-2-oxazoline) were prepared in the form of flexible and transparent films by casting of aqueous solutions with subsequent solvent evaporation. Samples of pure chitosan films without the addition of ciprofloxacin did not demonstrate antibacterial activity against Staphylococcus aureus and Escherichia coli. The CHI/POZ films showed some antimicrobial properties with respect to Escherichia coli, but did not show an ability to inhibit the growth of Staphylococcus aureus. Polymer films with CF showed antimicrobial activity against both strains of bacteria. Pure chitosan films with CF demonstrated the lowest drug release as a result of possible electrostatic attraction between the amino-groups of chitosan and carboxylic groups of ciprofloxacin hydrochloride. Films based on pure chitosan and its blends with poly(2-ethyl-2-oxazoline) exhibited mucoadhesive properties with respect to freshly excised sheep vaginal tissue. These formulations could potentially be used as mucoadhesive films for vaginal drug delivery.

Supplementary Materials: The following are available online at http://www.mdpi.com/1996-1944/13/7/1709/s1, Figure S1: A calibration curve used to determine the amount of released ciprofloxacin (CF) from chitosan based films, Figures S2 and S3: Exemplary detachment profiles of CHI (100) and CHI/POZ (40:60) films.

Author Contributions: G.K.A. (Investigation, writing - original draft); D.B.K. (formal analysis, visualization, manuscript editing), G.S.I. (project administration, supervision, funding acquisition), D.S.K. (investigation), Z.A.I. (investigation), S.E.K. (funding acquisition, resources), V.V.K. (conceptualization, funding acquisition, methodology, supervision, manuscript editing). All authors have read and agreed to the published version of the manuscript.

Funding: This research work was supported by the Ministry of Education and Science of the Republic of Kazakhstan, grant number AP08052780; and the European Union's Horizon 2020 research and innovation programme under the Marie Skłodowska-Curie grant agreement Nanopol 823883.

Acknowledgments: The authors are grateful to Zhanibek Assylkhanov (Al-Farabi Kazakh National University, Kazakhstan) for his technical assistance with in vitro experiments.

Conflicts of Interest: The authors declare no conflict of interest.

\section{References}

1. Hussain, A.; Ahsan, F. The vagina as a route for systemic drug delivery. J. Control. Release 2005, 103, 301-313. [CrossRef] [PubMed]

2. Vermani, K.; Garg, S. The scope and potential of vaginal drug delivery. Pharm. Sci. Technol. Today 2000, 3 , 359-364. [CrossRef]

3. Das Neves, J.; Bahia, M. Gels as vaginal drug delivery systems. Int. J. Pharm. 2006, 318, 1-14. [CrossRef] [PubMed]

4. Jensen, J.T. Vaginal ring delivery of selective progesterone receptor modulators for contraception. Contraception 2012, 87, 314-318. [CrossRef] [PubMed]

5. Cook, M.; Brown, M.B. Polymeric gels for intravaginal drug delivery. J. Control. Release 2018, 270, $145-157$. [CrossRef] [PubMed] 
6. Machado, R.M.; Palmeira-De-Oliveira, R.; Palmeira-De-Oliveira, A.; De Oliveira, J.M. Vaginal Films for Drug Delivery. J. Pharm. Sci. 2013, 102, 2069-2081. [CrossRef] [PubMed]

7. Khutoryanskiy, V.V. Mucoadhesive Materials and Drug Delivery Systems; John Wiley \& Sons, Ltd.: Chichester, UK, 2014.

8. Cook, M.T.; Khutoryanskiy, V.V. Mucoadhesion and mucosa-mimetic materials-A mini-review. Int. J. Pharm. 2015, 495, 991-998. [CrossRef]

9. Albarkah, Y.A.; Green, R.J.; Khutoryanskiy, V.V. Probing the mucoadhesive interactions between porcine gastric mucin and some water-soluble polymers. Macromol. Biosci. 2015, 15, 1546-1553. [CrossRef]

10. Brannigan, R.; Khutoryanskiy, V.V. Synthesis and evaluation of mucoadhesive acryloyl-quaternized PDMAEMA nanogels for ocular drug delivery. Colloids Surfaces B: Biointerfaces 2017, 155, 538-543. [CrossRef]

11. Jelkmann, M.; Menzel, C.; Baus, R.A.; Ausserhofer, P.; Baecker, D.; Gust, R.; Bernkop-Schnürch, A.; Ausserhofer, P. Chitosan: The One and Only? Aminated Cellulose as an Innovative Option for Primary Amino Groups Containing Polymers. Biomacromolecules 2018, 19, 4059-4067. [CrossRef]

12. Jelkmann, M.; Leichner, C.; Menzel, C.; Kreb, V.; Bernkop-Schnürch, A. Cationic starch derivatives as mucoadhesive and soluble excipients in drug delivery. Int. J. Pharm. 2019, 570, 118664. [CrossRef] [PubMed]

13. Sogias, I.A.; Williams, A.; Khutoryanskiy, V.V. Why is Chitosan Mucoadhesive? Biomacromolecules 2008, 9, 1837-1842. [CrossRef] [PubMed]

14. Sahariah, P.; Másson, M. Antimicrobial Chitosan and Chitosan Derivatives: A Review of the Structure-Activity Relationship. Biomacromolecules 2017, 18, 3846-3868. [CrossRef] [PubMed]

15. Ways, T.M.M.; Lau, W.M.; Khutoryanskiy, V.V. Chitosan and its derivatives for application in mucoadhesive drug delivery systems. Polymers 2018, 10, 267. [CrossRef] [PubMed]

16. Luo, K.; Yin, J.; Khutoryanskaya, O.V.; Khutoryanskiy, V.V. Mucoadhesive and elastic films based on blends of chitosan and hydroxyethylcellulose. Macromol. Biosci. 2008, 8, 184-192. [CrossRef] [PubMed]

17. Khoo, C. Oral gingival delivery systems from chitosan blends with hydrophilic polymers. Eur. J. Pharm. Biopharm. 2003, 55, 47-56. [CrossRef]

18. Yeh, J.-T.; Chen, C.-L.; Huang, K.S.; Nien, Y.H.; Chen, J.L.; Huang, P.Z. Synthesis, characterization, and application of PVP/chitosan blended polymers. J. Appl. Polym. Sci. 2006, 101, 885-891. [CrossRef]

19. Li, J.; Zivanovic, S.; Davidson, P.M.; Kit, K. Characterization and comparison of chitosan/PVP and chitosan/PEO blend films. Carbohydr. Polym. 2010, 79, 786-791. [CrossRef]

20. Sizílio, R.; Galvão, J.; Trindade, G.; Pina, L.; Andrade, L.; Gonsalves, J.; Lira, A.A.M.; Chaud, M.V.; Alves, T.F.; Arguelho, M.; et al. Chitosan/pvp-based mucoadhesive membranes as a promising delivery system of betamethasone-17-valerate for aphthous stomatitis. Carbohydr. Polym. 2018, 190, 339-345. [CrossRef]

21. Nakano, Y.; Bin, Y.; Bando, M.; Nakashima, T.; Okuno, T.; Kurosu, H.; Matsuo, M. Structure and Mechanical Properties of Chitosan/Poly(Vinyl Alcohol) Blend Films. Macromol. Symp. 2007, 258, 63-81. [CrossRef]

22. Abraham, A.; Soloman, P.; Rejini, V. Preparation of Chitosan-Polyvinyl Alcohol Blends and Studies on Thermal and Mechanical Properties. Procedia Technol. 2016, 24, 741-748. [CrossRef]

23. Hoogenboom, R. Poly(2-oxazoline)s: A Polymer Class with Numerous Potential Applications. Angew. Chem. Int. Ed. 2009, 48, 7978-7994. [CrossRef] [PubMed]

24. Glassner, M.; Vergaelen, M.; Hoogenboom, R. Poly(2-oxazoline)s: A comprehensive overview of polymer structures and their physical properties. Polym. Int. 2017, 67, 32-45. [CrossRef]

25. Policianova, O.; Brus, J.; Hruby, M.; Urbanova, M.; Zhigunov, A.; Kredatusova, J.; Kobera, L. Structural Diversity of Solid Dispersions of Acetylsalicylic Acid as Seen by Solid-State NMR. Mol. Pharm. 2014, 11, 516-530. [CrossRef]

26. Fael, H.; Ràfols, C.; Demirel, A.L. Poly(2-Ethyl-2-Oxazoline) as an Alternative to Poly(Vinylpyrrolidone) in Solid Dispersions for Solubility and Dissolution Rate Enhancement of Drugs. J. Pharm. Sci. 2018, 107, 2428-2438. [CrossRef]

27. Boel, E.; Smeets, A.; Vergaelen, M.; De La Rosa, V.R.; Hoogenboom, R.; Mooter, G.V.D. Comparative study of the potential of poly(2-ethyl-2-oxazoline) as carrier in the formulation of amorphous solid dispersions of poorly soluble drugs. Eur. J. Pharm. Biopharm. 2019, 144, 79-90. [CrossRef]

28. Moustafine, R.I.; Viktorova, A.S.; Khutoryanskiy, V.V. Interpolymer complexes of carbopolß971 and poly(2-ethyl-2-oxazoline): Physicochemical studies of complexation and formulations for oral drug delivery. Int. J. Pharm. 2019, 558, 53-62. [CrossRef] 
29. Abilova, G.K.; Kaldybekov, D.; Ozhmukhametova, E.K.; Saimova, A.Z.; Kazybayeva, D.S.; Irmukhametova, G.S.; Khutoryanskiy, V.V. Chitosan/poly(2-ethyl-2-oxazoline) films for ocular drug delivery: Formulation, miscibility, in vitro and in vivo studies. Eur. Polym. J. 2019, 116, 311-320. [CrossRef]

30. Boateng, J.; Popescu, A. Composite bi-layered erodible films for potential ocular drug delivery. Colloids Surfaces B: Biointerfaces 2016, 145, 353-361. [CrossRef]

31. Karki, S.; Kim, H.; Na, S.-J.; Shin, D.; Jo, K.; Lee, J. Thin films as an emerging platform for drug delivery. Asian J. Pharm. Sci. 2016, 11, 559-574. [CrossRef]

32. Hallander, H.O.; Laurell, G. Identification of Cephalosporin-Resistant Staphylococcus aureus with the Disc Diffusion Method. Antimicrob. Agents Chemother. 1972, 1, 422-426. [CrossRef] [PubMed]

33. Owen, D.H.; Katz, D.F. A vaginal fluid simulant. Contracept. 1999, 59, 91-95. [CrossRef]

34. Mulu, W.; Yimer, M.; Zenebe, Y.; Abera, B. Common causes of vaginal infections and antibiotic susceptibility of aerobic bacterial isolates in women of reproductive age attending at Felegehiwot Referral Hospital, Ethiopia: A cross sectional study. BMC Women's Heal. 2015, 15, 42. [CrossRef] [PubMed]

35. Abdelkader, H.; Pierscionek, B.; Alany, R.G. Novel in situ gelling ocular films for the opioid growth factor-receptor antagonist-naltrexone hydrochloride: Fabrication, mechanical properties, mucoadhesion, tolerability and stability studies. Int. J. Pharm. 2014, 477, 631-642. [CrossRef]

36. Hillery, A.M.; Lloyd, A.W.; Swarbrick, J. Drug Delivery and Targeting for Pharmacists and Pharmaceutical Scientists; CRC Press, Taylor \& Francis: Boca Raton, FL, USA, 2001.

37. Raafat, D.; Von Bargen, K.; Haas, A.; Sahl, H.-G. Insights into the Mode of Action of Chitosan as an Antibacterial Compound. Appl. Environ. Microbiol. 2008, 74, 3764-3773. [CrossRef]

38. Raafat, D.; Sahl, H.-G. Chitosan and its antimicrobial potential - a critical literature survey. Microb. Biotechnol. 2009, 2, 186-201. [CrossRef]

39. Alexander, N.J.; Baker, E.; Kaptein, M.; Karck, U.; Miller, L.; Zampaglione, E. Why consider vaginal drug administration? Fertil. Steril. 2004, 82, 1-12. [CrossRef]

40. Lang, W.R. Vaginal acidity and pH. A review. Obstet. Gynecol. Surv. 1955, 10, 546-560. [CrossRef]

41. Jalil, A.; Asim, M.H.; Le, N.-M.N.; Laffleur, F.; Matuszczak, B.; Tribus, M.; Bernkop-Schnürch, A. S-protected gellan gum: Decisive approach towards mucoadhesive antimicrobial vaginal films. Int. J. Boil. Macromol. 2019, 130, 148-157. [CrossRef]

42. Davidovich-Pinhas, M.; Bianco-Peled, H. Mucoadhesion: A review of characterization techniques. Expert Opin. Drug Deliv. 2010, 7, 259-271. [CrossRef]

43. Ruiz-Rubio, L.; Alonso, M.L.; Pérez-Álvarez, L.; Alonso, R.M.; Vilas, J.L.; Khutoryanskiy, V.V. Formulation of Carbopol@/Poly(2-ethyl-2-oxazoline)s mucoadhesive tablets for buccal delivery of hydrocortisone. Polymers 2018, 10, 175. [CrossRef] [PubMed]

44. Sogias, I.A.; Williams, A.C.; Khutoryanskiy, V.V. Chitosan-based mucoadhesive tablets for oral delivery of ibuprofen. Int. J. Pharm. 2012, 436, 602-610. [CrossRef] [PubMed] 